\title{
Identification of new signaling components in the sensory epithelium of human saccule
}

\author{
Eva Degerman ${ }^{1}$, Uwe Rauch ${ }^{2}$, Olga Göransson ${ }^{1}$, Sven Lindberg ${ }^{3}$, Anna Hultgårdh ${ }^{2}$ and Måns Magnusson ${ }^{3}$ \\ ' Section for Diabetes, Metabolism and Endocrinology, Department of Experimental Medical Sciences, Lund University, Lund, Sweden \\ 2 Section for Vascular Wall Biology, Department of Experimental Medical Sciences, Lund University, Lund, Sweden \\ ${ }^{3}$ Section for Otorhinolaryngology, Department of Clinical Sciences, Lund University and Skåne University Hospital, Lund, Sweden
}

\section{Edited by:}

Stefano Ramat, Università degli Studi

di Pavia, Italy

Reviewed by:

Antonella Palla, Zurich University

Hospital, Switzerland

Sonja Pyott, University of North

Carolina Wilmington, USA

*Correspondence:

Eva Degerman, Biomedical Center

C11, Lund University, 22184 Lund

Sweden.

e-mail: eva.degerman@med.lu.se
Objective: To locate components and target proteins of relevance for the cAMP and cGMP signaling networks including CAMP and cGMP phosphodiesterases (PDEs), salt-inducible kinases (SIKs), subunits of $\mathrm{Na}+, \mathrm{K}+-$-ATPases, and aquaporins (AOPs) in the human saccule.

Methods: The human saccule was dissected out during the removal of vestibular schwannoma via the translabyrinthine approach and immediately fixed. Immunohistochemistry was performed using PDE, SIK, $\mathrm{Na}^{+}, \mathrm{K}^{+}$-ATPase, and AOP antibodies. Results: PDEs selective for CAMP (PDE4A, PDE4D, and PDE8A) and cGMP (PDE9A) as well a dual specificity PDE (PDE10A) were detected in the sensory epithelium of the saccule. Furthermore, AQP2, 4, and 9, SIK1 and the $\alpha-1$ subunit of the $\mathrm{Na}^{+}, \mathrm{K}^{+}$-ATPase were detected. Conclusion: cAMP and cGMP are important regulators of ion and water homeostasis in the inner ear. The identification of PDEs and SIK1 in the vestibular system offers new treatment targets for endolymphatic hydrops. Exactly how the PDEs are connected to SIK1 and the SIK1 substrate $\mathrm{Na}^{+}, \mathrm{K}^{+}$-ATPase and to AQPs 2, 4, 9 remains to be elucidated. The dissection of the signaling networks utilizing these components and evaluating their roles will add new basic knowledge regarding inner ear physiology.

Keywords: saccule, immunohistochemistry, cAMP, cGMP, cyclic nucleotide phosphodiesterase, salt-inducible kinase, $\mathrm{Na}$, K-ATPase, aquaporin

\section{INTRODUCTION}

The membranous labyrinth of the inner ear is a sensory system for sound, motion, and gravity, consisting of the cochlea, vestibular system, and the endolymphatic sac. The lumen of the membranous labyrinth is filled with endolymph, $\mathrm{a} \mathrm{K}^{+}$-rich, positively polarized fluid, whereas the surrounding spaces are filled with perilymph, with a composition similar to regular extracellular fluid (Andrews, 2004; Thalmann et al., 2006; Lang et al., 2007). Dysregulation of ion and water homeostasis in the inner ear is believed to result in endolymphatic hydrops, a condition associated with vertigo and hearing loss (Semaan et al., 2005). Several studies indicate an important role for the cAMP second messenger system in the regulation of ion and water homeostasis in the inner ear. For example, cAMP has been shown to regulate the secretion of $\mathrm{K}^{+}$into the endolymph (Wangemann, 2002; Salt and Plontke, 2010) and it has been suggested that water homeostasis in the inner ear is regulated in part via the vasopressin-cAMP-aquaporin (AQP) 2 water channel system (Takeda and Taguchi, 2009) in the same fashion as in the kidney (Lang et al., 2007; Noda et al., 2010). When it comes to the cGMP signaling system and the regulation of ion and water homeostasis in the inner ear, less is known. However, roles for the nitric oxide-cGMP and the atrial natriuretic peptide (ANP)cGMP systems have been suggested (Fessenden and Schacht, 1998;

Abbreviations: Abbreviations: AQP, aquaporin; DAPI, 4,6-diamidino-2phenylindole; GFAP, glial fibrillary acidic protein; PDE, phosphodiesterase; SIK, salt-inducible kinase.
Semaan et al., 2005; Borghi et al., 2006). ANP has hypotensive and hypovolemic effects which are mediated via increases in intracellular cGMP levels (Ahluwalia et al., 2004). Hypotension has been suggested to play a role in inner ear disorders (Pirodda et al., 1997, 2001) and ANP receptors are expressed in the inner ear (Long et al., 2010).

By hydrolyzing cAMP and cGMP, cyclic nucleotide phosphodiesterases (PDEs) regulate a wide variety of biological responses mediated by these second messenger molecules. Mammalian PDEs can be sorted into 11 functionally distinct, highly regulated, and structurally related families (Manganiello et al., 2006; Conti and Beavo, 2007). These PDE families differ in their primary sequences, substrate affinities, and catalytic properties, sensitivity to effectors and inhibitors, responses to regulatory molecules, and cellular functions. Some PDE families are specific for cAMP hydrolysis (PDEs 4, 7, 8), others are cGMP-specific (PDEs 5, 6, 9), and some hydrolyze both cGMP and cAMP (PDEs 1, 2, 3, 10,11). Most cells contain representatives of more than one PDE gene family, but in different amounts, proportions, and subcellular locations. By virtue of their distinct intrinsic characteristics and their intracellular targeting to different subcellular locations, different PDEs integrate multiple cellular inputs and modulate the amplitude, duration, termination, and specificity of cyclic nucleotide signals and actions (Manganiello et al., 2006; Conti and Beavo, 2007; Houslay, 2010).

Very little is known about PDEs and how they relate to other signaling networks and targets in the inner ear. In this study we 
focus on PDEs and some selected potential targets for PDEs in the human saccule namely AQP water channels, salt-inducible kinases (SIKs) and $\mathrm{Na}^{+}, \mathrm{K}^{+}$-ATPases. AQP water channels are known to play a crucial role in water homeostasis not only in the kidney but also in the inner ear (Lopez et al., 2007; Takeda and Taguchi, 2009; Ishiyama et al., 2010). $\mathrm{Na}^{+}, \mathrm{K}^{+}$-ATPases which couple the hydrolysis of ATP to transport of $\mathrm{Na}^{+}$ions out of and $\mathrm{K}^{+}$ions into the cell have previously been shown to be involved in endolymph ionexchange processes (Kuijpers and Bonting, 1970). Recently the $\alpha$ subunit of $\mathrm{N}^{+}, \mathrm{K}^{+}$-ATPase was shown to be regulated by SIK1 in kidney cells (Sjöström et al., 2007; Jaitovich and Bertorello, 2010; Taub et al., 2010).

The aim of this study is to evaluate the expression pattern of PDEs and selected potential downstream targets in human saccule.

\section{MATERIALS AND METHODS TISSUE SAMPLING AND PREPARATIONS}

Human saccule was obtained during the removal of vestibular schwannoma via the translabyrinthine approach. As the specimens were obtained at surgery no on bloc fixation of bone and inner ear structures was possible. However, the structures of the vestibulum could be defined before retrieval. The sample was immediately fixed in HistoChoice (Amresco) in phosphate buffer saline (PBS) for $12 \mathrm{~h}$, soaked in $30 \%$ sucrose in PBS at $4^{\circ} \mathrm{C}$ over night and then embedded in Tissue Tec OCT Compound (Gene Research Lab.). Eight micromolar thick sections were cut with a cryostat and collected on slides (super-frost-plus, Fischer Scientific). Eight consecutive tissue sections were placed on each glass slide. Tissue sections were stored at $-80^{\circ} \mathrm{C}$ until use. The procedures were evaluated by the responsible committee at Lund University on human experimentation and were in accordance with the Helsinki Declaration of 1975, as revised in 1983.

\section{IMMUNOHISTOCHEMISTRY}

Before being immunohistochemically stained, sections were thawed and allowed to air-dry for $10 \mathrm{~min}$. Next, a circle surrounding each tissue section was drawn with a hydrophobic pen (Dako, Denmark). Tissue sections were covered with 5\% normal goat serum diluted in PBS for $1 \mathrm{~h}$ (approximately $30 \mu \mathrm{l}$ per section). Subsequently, the specimens were exposed overnight at $4^{\circ} \mathrm{C}$ in a humid chamber to antibodies specific for PDE4A, PDE4D, PDE8A, PDE9A, PDE10A, AQP2, AQP4, AQP9, SIK1, $\alpha-1$ subunit of $\mathrm{Na}^{+}, \mathrm{K}^{+}$-ATPase, laminin $\gamma 1$, pan-laminin, caveolin-1, and glial fibrillary acidic protein (GFAP). Table 1 provides information regarding the antibodies including source, cat\#, immunogen, and positive/negative controls. All antibodies were diluted 1:75 in 5\% normal goat serum (Invitrogen). At the end of the incubations, the tissue sections were rinsed in PBS $(3 \times 15 \mathrm{~min})$. Secondary goat anti rabbit antibodies (labeled with Alexa 555) or goat anti mouse antibodies (labeled with Alexa 488; Invitrogen, diluted 1:200), were applied to the tissue sections and incubated for $2 \mathrm{~h}$ at room temperature in the dark. At the end of the incubation, sections were washed with PBS and in some experiments 4,6-diamidino-2-phenylindole (DAPI,

Table 1 | Antibodies: source, type, immunogen, positive/negative controls.

\begin{tabular}{|c|c|c|}
\hline Antibody/source/cat \#/antibody type & Immunogen & Positive/negative control \\
\hline $\begin{array}{l}\text { AOP2 (H-40)/Santa Cruz/sc 28629/rabbit } \\
\text { polyclonal }\end{array}$ & $\begin{array}{l}\text { Amino acid } 232-291 \text { within the } \text { C-terminal } \\
\text { domain of human AQP2 }\end{array}$ & $\operatorname{Ref}^{1} /$ omission of the antibody (no reaction) \\
\hline $\begin{array}{l}\text { AQP4 (H-80)/Santa Cruz/sc 20812/rabbit } \\
\text { polyclonal }\end{array}$ & $\begin{array}{l}\text { Amino acid } 244-323 \text { within the C-terminal } \\
\text { domain of human AQP4 }\end{array}$ & Refs $^{2,3} /$ omission of the antibody (no reaction) \\
\hline AQP 9/Abcam/ab84828/rabbit polyclonal & $\begin{array}{l}\text { A } 15 \text { amino acid synthetic peptide from the } \\
\text { N-terminal of human AQP9 }\end{array}$ & $\begin{array}{l}\text { Stains AQP9 using immunohistochemistry on } \\
\text { human liver sections (Abcam)/omission of the } \\
\text { antibody (no reaction) }\end{array}$ \\
\hline $\begin{array}{l}\text { PDE4A, PDE4D, PDE8A, PDE9A, } \\
\text { PDE10A/Scottish Biomedical/rabbit polyclonal }\end{array}$ & $\begin{array}{l}\text { Designed from the } \mathrm{C} \text {-terminal region from } \\
\text { respective human enzyme }\end{array}$ & $\begin{array}{l}\text { Refs }^{4,5} \text { (PDEs 8A, 9A, 10A) and Omar et al. (unpub- } \\
\text { lished) (PDE4A and 4D)/omission of the antibody } \\
\text { (no reaction) }\end{array}$ \\
\hline $\begin{array}{l}\mathrm{N}^{+} / \mathrm{K}^{+} \text {ATPase } \alpha-1 / \text { Millipore/05-369/mouse } \\
\text { monoclonal }\end{array}$ & $\begin{array}{l}\text { Purified } \mathrm{N}^{+}, \mathrm{K}^{+} \text {-ATPase isolated from membrane } \\
\text { fractions of rat kidney outer medulla }\end{array}$ & Refs $^{6,7} /$ omission of the antibody (no reaction) \\
\hline SIK1 (Y-20)/Santa Cruz/sc83754/rabbit polyclonal & A peptide within an internal region of human SIK1 & Ref $f^{8} /$ mission of the antibody (no reaction) \\
\hline $\begin{array}{l}\text { Caveolin-1 (N-20)/Santa Cruz/sc-894/rabbit } \\
\text { polyclonal }\end{array}$ & A peptide at the $\mathrm{N}$-terminal of human caveolin-1 & $\operatorname{Refs}^{9,10} /$ omission of the antibody (no reaction) \\
\hline Laminin $\gamma 1 /$ Gift Dr. Sorokin/mouse monoclonal & Rat glomerular basement membrane membrane & 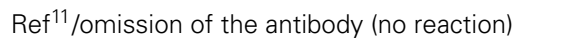 \\
\hline $\begin{array}{l}\text { Pan-laminin 1/455/Gift Dr. Sorokin/rabbit } \\
\text { polyclonal }\end{array}$ & Mouse laminin $\alpha 1, \beta 1, \gamma 1$ & Ref ${ }^{12} /$ mission of the antibody (no reaction) \\
\hline $\begin{array}{l}\text { Glial fibrillary acidic } \\
\text { protein/Sigma-Aldrich/G3893/mouse monoclonal }\end{array}$ & Purified GFAP from pig spinal cord & Ref ${ }^{13} / o m i s s i o n$ of the antibody (no reaction) \\
\hline
\end{tabular}

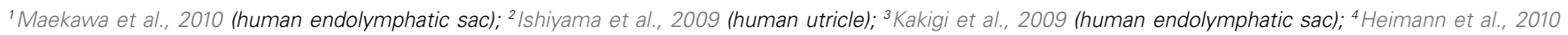
(human pancreatic islets); ${ }^{5}$ Omar et al., accepted for publication (human adipose tissue); ${ }^{6}$ Kobayashi et al., 2009 (rat erythrocytes); ${ }^{7}$ Yang et al., 2011 (mouse cochlea, stria vascularis capillaries); ${ }^{8}$ Yoon et al., 2009 (mouse liver); ${ }^{~ N i l s s o n ~ e t ~ a l ., ~} 2006$ (rat adipocytes); 10 Noël et al., 2009 (rat astrocytes); ${ }^{11}$ Sanes et al., 1990 (muscle fiber, nerve trunk, kidney, blood vessels from rat, rabbit, guinea pig and human); ${ }^{12}$ /shiyama et al., 2010 (human utricle); ${ }^{13}$ Agrawal et al., 2006 (mouse brain). 
Invitrogen) was added for $10 \mathrm{~min}$ to visualize all cell nuclei. At the end of the incubation, the sections were washed in PBS and mounted with Vectashield (Vector Laboratories). Sections were observed using a camera-equipped fluorescence microscope. Images were obtained using a Zeiss Axiophot 2 microscope and a Hamamatsu C4742-95 camera with OpenLab 5 software (Improvision) for image processing. The quality of the microdissected saccule was determined by staining with hematoxylin and eosin. For all staining, several sections from three saccules were analyzed.

\section{RESULTS}

To map the expression pattern of PDEs and other signaling components and targets of relevance for the cAMP and cGMP signaling networks and for the regulation of water and ion homeostasis, an immunohistochemistry approach was used.

Figure 1A shows hematoxylin and eosin staining of a representative section of human saccule. The sensory epithelium with nuclei at several layers, non-sensory epithelium, otoconia, the endolymph compartment, as well as the stroma, with cells, can be seen. Glial fibrillary acidic protein (GFAP) antibodies were used to stain supporting cells in the sensory epithelium (Figures 1B-D; Lopez et al., 2007). Figure 1B is an overview showing the sensory epithelium and the non-sensory epithelium. Figures 1C,D show supporting cells as well as hair cells.

As shown by representative photographs (Figures $2 \mathrm{~A}-\mathrm{J}$ ), the sensory epithelium of the saccule expresses PDEs specific for cAMP (PDE4A, PDE4D, and PDE8A), for cGMP (PDE9A), and a dual specificity enzyme (PDE10A). The immunoreactivity to PDE10A was mainly found in the apical part of the epithelium

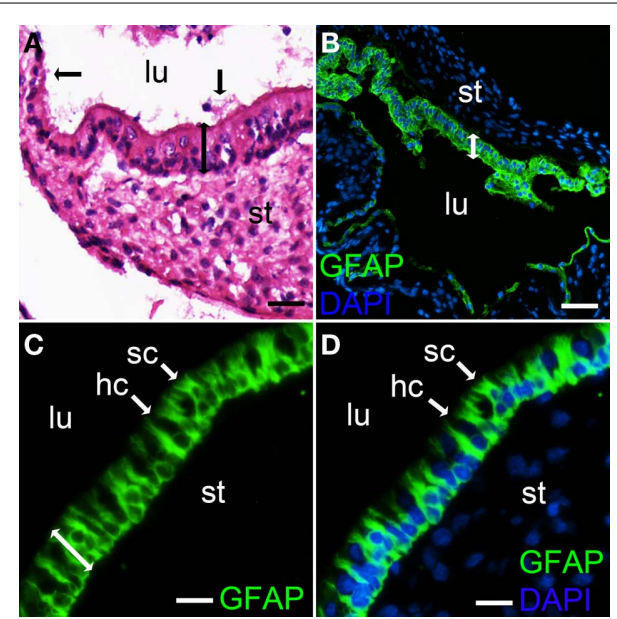

FIGURE 1 | Hematoxylin and eosin and GFAP staining of a section from human saccule. Hematoxylin and eosin staining shows the sensory epithelium with nuclei at several layers (bar with two arrow heads), otoconia (vertical bar with one arrow head) and a section of the non sensory saccule epithelium (horizontal bar with one arrow head) (A). Glial fibrillary acidic protein (GFAP) staining was used to indicate supporting cells in the sensory epithelium (B-D). Merged photos of GFAP and DAPI, to stain nuclei (B,D). Supporting cells (sc), hair cells (hc) (non stained) and sensory epithelium (bar with two $m \mu$ arrow heads) are indicated (C,D). Lumen (lu), stroma (st). Bars $20 \mathrm{M}$ (C,D). $\mu \mathrm{M}$ (B), $15 \mu$ (A), 40.
(Figures 2I,J). As is shown in Figures 2A,B, no significant staining in the non-sensory epithelium was obtained for PDE4A. This was also the case for the other PDEs investigated (data not shown).

The water channel AQP2 is known to be regulated by vasopressin in a cAMP-dependent manner (Takeda and Taguchi, 2009) as has been investigated in detail in kidney cells (Lang et al., 2007). Immunoreactivity to AQP2 is expressed in the sensory epithelium of the human saccule as well as in stromal cells (Figures $3 \mathrm{~A}, \mathrm{C}$ ) but not in the non-sensory epithelium (data not shown). The expression of AQP4 and AQP9, two other AQPs known to be regulated in CAMP- and cGMP-dependent manners, were then investigated. Immunoreactivity to AQP4 was detected in the basolateral part of the sensory epithelium (Figures 3D-F) as well as in non-sensory epithelium (data not shown). Basolateral location of AQP4 was confirmed by co-expression with laminin 1, a basal membrane protein (Figures $\mathbf{3 G}, \mathbf{H}$ ). In previous studies AQP4 has been shown to co-stain with flotillin-1 in brain astrocytes, indicating raft location of AQP4 (Noël et al., 2009). We found no staining for flotillin-1 (unpublished observation) in human saccule sensory epithelium, however, immunoreactivity of another raft marker, caveolin-1, was detected in the sensory epithelium (Figure 3B) but not in the non-sensory epithelium (data not shown). Immunoreactivity to AQP9 was detected partially in the basolateral part of the epithelium as indicated by co-stained with laminin 1. AQP9 immunoreactivity was not seen in the non-sensory epithelium (Figures 3I,J).

The expression of SIK1, another cAMP-regulated target of relevance for ion and water homeostasis, was investigated. Immunoreactivity to SIK1 was detected in the sensory epithelium (Figures 4A,B). SIK1 has been shown to regulate the activity of $\mathrm{Na}^{+}, \mathrm{K}^{+}$-ATPase in kidney cells (Jaitovich and Bertorello, 2010; Taub et al., 2010), and AQP4 has been shown to associate with a $\mathrm{Na}^{+}, \mathrm{K}^{+}$-ATPase (Illarionova et al., 2010). The $\alpha-1$ subunit of the $\mathrm{Na}^{+}, \mathrm{K}^{+}$-ATPase was expressed in the human saccule epithelium and immunostaining was partially localized to the basolateral part of the cells as shown by co-staining with laminin 1 (Figures 5A-C).

Figure 6 shows a schematic view of the possible interrelation of signaling components and targets studied in this work. Included in the figure is also cAMP-dependent protein kinase (PKA) and cGMP-dependent protein kinase (PKG), the major mediators of cAMP and cGMP effects, respectively. PDEs with the function to specifically catalyze the hydrolysis of cAMP and cGMP in response to signaling inputs, such as vasopressin, catecholamines, atrio natriuretic peptide, and nitric oxide may be important in the regulation of water and ion homeostasis in the inner ear by having impact on SIK1 and the SIK1 substrate $\mathrm{Na}^{+}, \mathrm{K}^{+}$-ATPase as well as on a number of AQPs. The presence of these signaling networks in the inner ear needs to be verified and studied at the functional level.

\section{DISCUSSION}

cAMP and cGMP have important roles in the regulation of water and ion homeostasis in the inner ear (Fessenden and Schacht, 1998; Wangemann, 2002; Semaan et al., 2005; Salt and Plontke, 2010). Regulation of the cyclic nucleotides occurs at the level of synthesis 
by adenylate and guanylate cyclases as well as at the level of degradation by PDEs. PDEs have been studied in many different cell types and these have been shown to express different members of the 11 PDE families (Manganiello et al., 2006; Conti and Beavo,
2007). Here we show for the first time that PDE proteins are expressed in the inner ear. More specifically, we demonstrate the expression of PDEs selective for cAMP (PDE4A, PDE4D, PDE8A) and for cGMP (PDE9A) as well as of a PDE hydrolyzing both
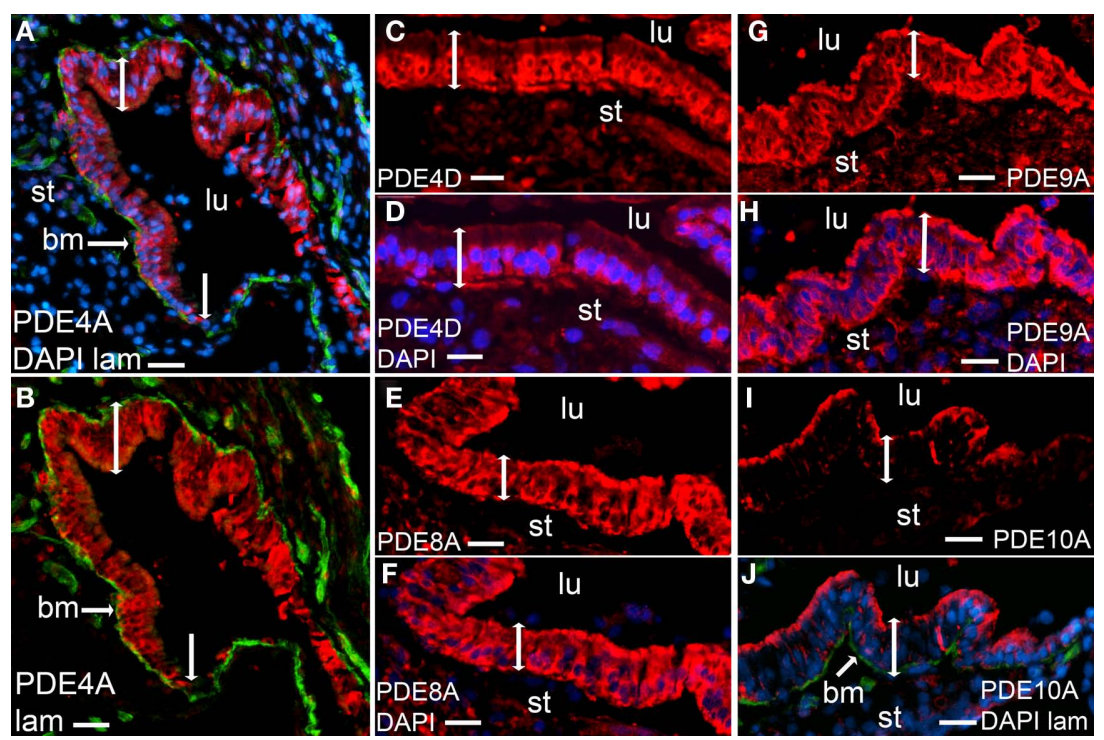

FIGURE 2 | Immunostaining of phosphodiesterases (red) in human saccules. Merged photos of PDE4A, laminin (green), and DAPI [blue (A)], merged photos of PDE4A and DAPI (B), PDE4D (C), merged photos of PDE4D and DAPI (D),PDE8A (E), merged photos of PDE8A and DAPI (F),
PDE9A (G), merged photos of PDE9A and DAPI (H), PDE10A (I), merged photos of PDE10A, laminin (green), and DAPI (J). Sensory epithelium (bar with two arrowheads), transition to non-sensory epithelium (vertical bar with one arrow head), lumen (lu), stroma (st). Bars $30 \mu \mathrm{m}$ (A,B), $20 \mu \mathrm{m}$ (C-J)
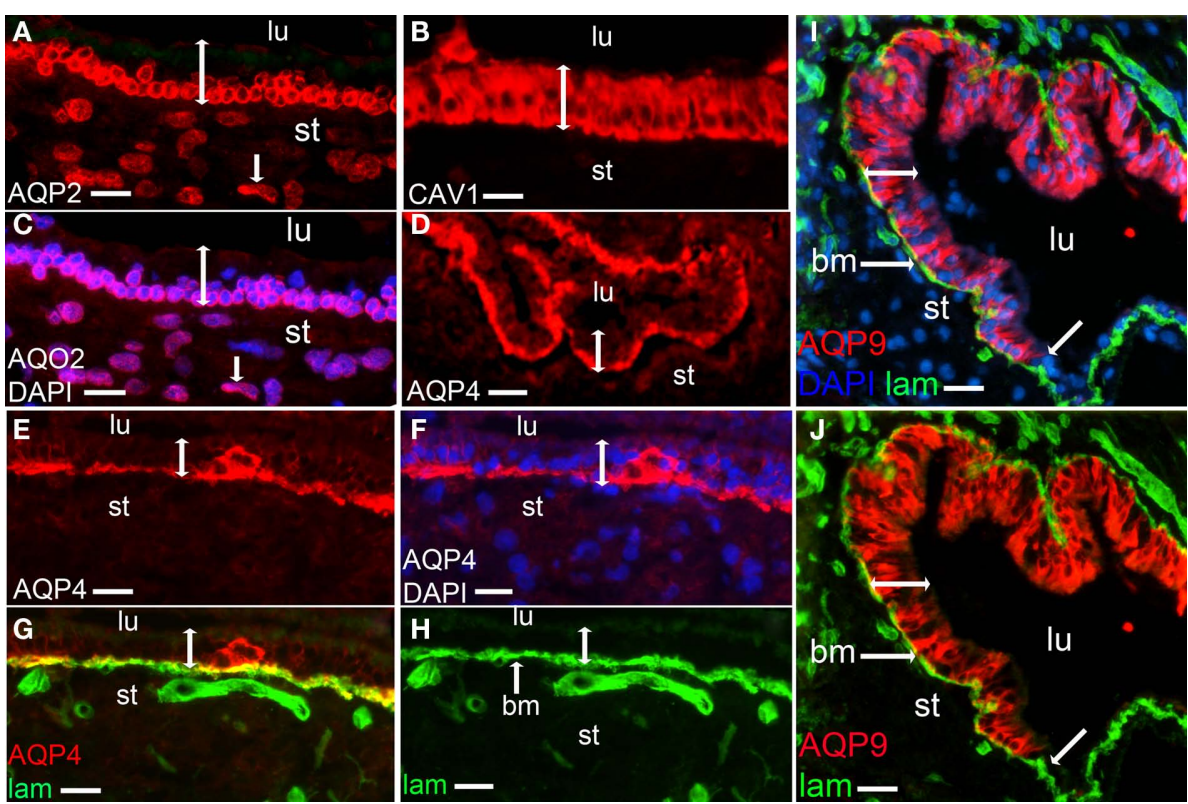

FIGURE 3 | Immunostaining of aquaporins (red). AQP2 (A), merged photos of AQP2 and DAPI [blue (C)], Caveolin-1 [red (B)], AQP4 (D,E), merged photos of AQP4 and DAPI (F), merged photos of AQP4 and laminin [green $(\mathbf{G})$ ], laminin [green $\mathbf{( H )}$ ], merged photos of AQP9, laminin and DAPI (I) and merged photos of AQP9 and laminin (J).
Lumen (lu), bm [basal membrane (G-J)], stroma (st), sensory epithelium (bar with two arrow heads), stromal cell (A,C, bar with one arrow head), transition to non sensory epithelium (I,J, bar with one arrow head). Bars $15 \mu \mathrm{m}$ (A,C), $12.5 \mu \mathrm{m}$ (B), $25 \mu \mathrm{m}$ (D), $15 \mu \mathrm{m}$ (E-H), $20 \mu \mathrm{m}(\mathbf{I}, \mathbf{J})$. 
cAMP and cGMP (PDE10A) in the sensory epithelium of human saccule. These enzymes could have a number of physiological roles when it comes to the regulation of cAMP- and cGMP-mediated processes in the saccule related to water and ion homeostasis. For example, PDE4 has been shown to have an important role in the regulation of vasopressin-induced translocation of AQP2 to the plasma membrane in cultured kidney cells (Stefan et al., 2007). In our study, AQP2 was detected in the human saccule together with two PDE4 members. Thus, it is possible that PDE4A and PDE4D control a cAMP pool involved in the regulation of AQP2 translocation. Functional studies indeed indicate an important role for AQP2 in the inner ear (Takeda et al., 2010), as is the case in the kidney. For example, it has been shown that expression of AQP2 is up-regulated in the cochlea and endolymphatic sac by the systemic application of vasopressin whereas it is down-regulated by systemic and local application of a vasopressin receptor 2 antagonist (OPC-31260; Takeda et al., 2010). The observation of high plasma vasopressin levels in Meniere's disease suggests that components in the vasopressin-cAMP-AQP2 system, including cAMP PDEs, are promising targets for the development of therapies for diseases characterized by vertigo and hearing loss. However, although the vasopressin-cAMP-AQP2 system is believed to be important for water homeostasis in the inner ear, exactly what the role is for this system in the human saccule is not known and needs further investigation. $\beta$ adrenergic receptors are known to mediate effects via the cAMP system. $\mathrm{K}^{+}$secretion in vestibular dark cells and chloride secretion by semicircular canal duct epithelium have been shown to be mediated via $\beta-1$ and $\beta-2$ adrenergic receptors, respectively

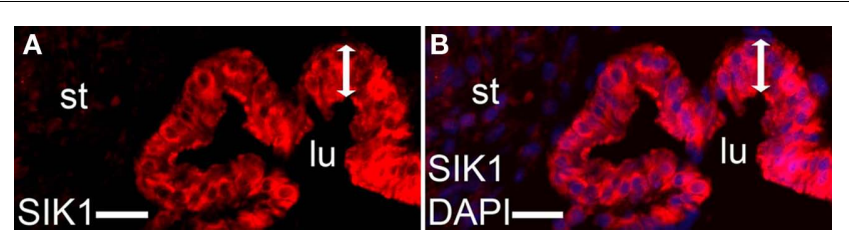

FIGURE 4 | Immunostaining of salt-inducible kinase (SIK) 1. SIK1 [(A) red], merged photos of SIK1 and DAPI [blue (B)]. Lumen (lu), stroma (st), sensory epithelium (bar with two arrowheads). Bars $25 \mu \mathrm{m}(\mathbf{A}, \mathbf{B})$.
(Wangemann et al., 1999; Milhaud et al., 2002). Exactly which PDEs are connected to the $\beta$-adrenergic systems in the inner ear is not yet know.

Two cGMP-degrading PDEs, PDE9A, and PDE10A, were shown to be expressed in the epithelium of human saccule. When it comes to the cGMP signaling system and the regulation of ion and water homeostasis in the inner ear much less is known as compared to the cAMP system. However, the cGMP-increasing hormone atrial natriuretic peptide has been suggested to regulate inner ear functions via the atrial natriuretic peptide receptor (Long et al., 2010), which is a membrane bound guanylate cyclase. Also, stimuli activating cGMP-dependent protein kinase

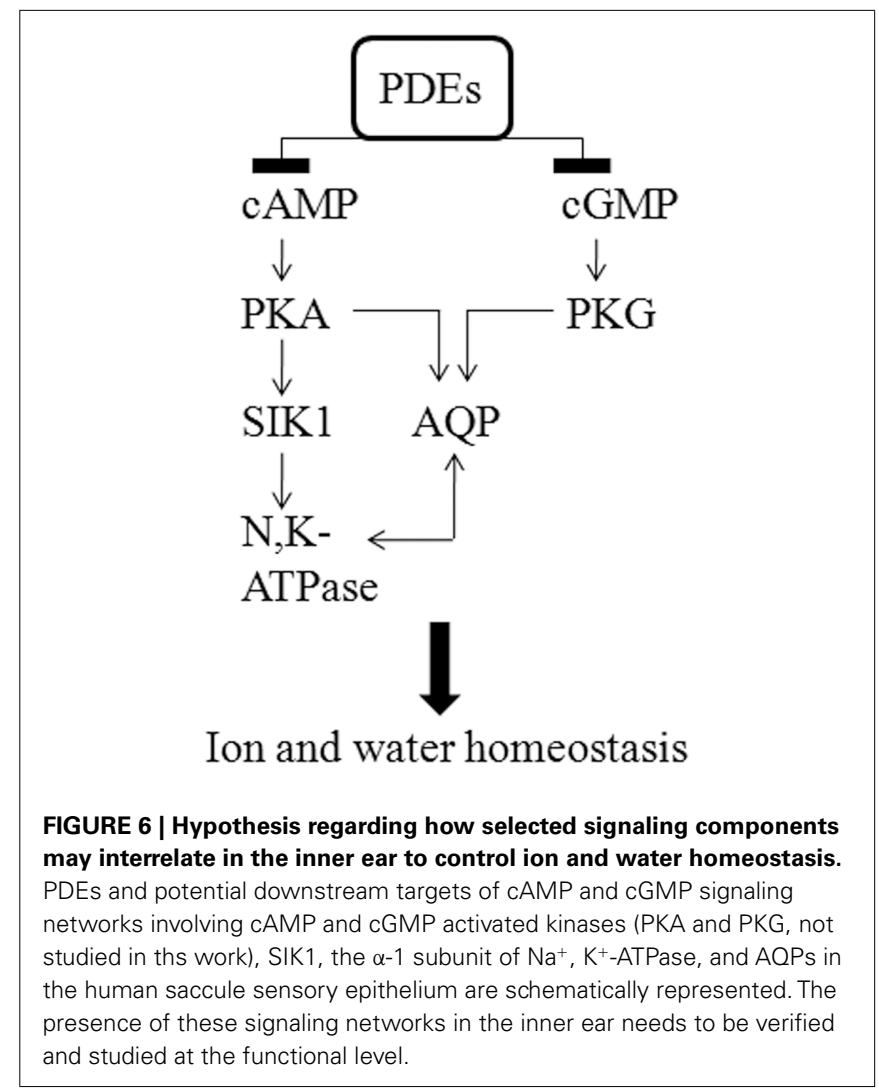

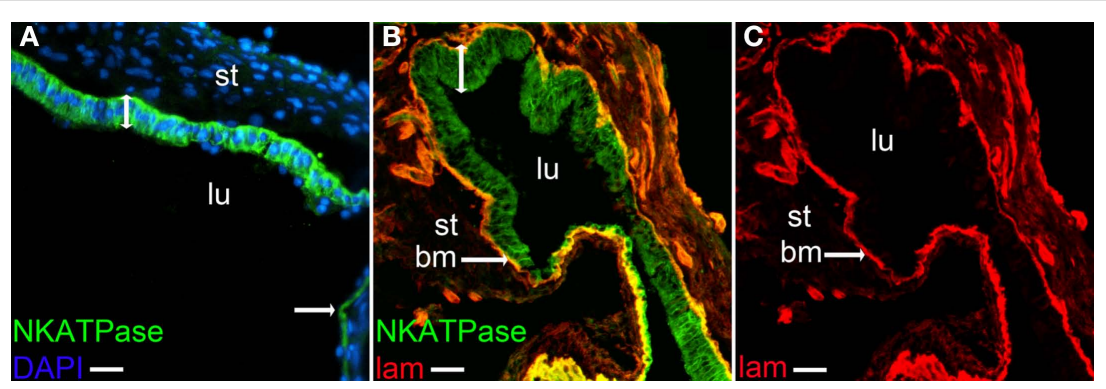

FIGURE 5 | Immunostaning of the $\alpha-\mathbf{1}$ subunit of the $\mathbf{N}^{+}, \mathbf{K}^{+}$-ATPase. Merged photos of $\mathrm{N}^{+}, \mathrm{K}^{+}$-ATPase and DAPI (A), merged photos of $\mathrm{N}^{+}, \mathrm{K}^{+}$-ATPase and laminin (B) and laminin (C). Lumen (lu), stroma (st), basal membrane (bm), non-sensory epithelium [bar with one arrowhead (A)]. Bars $25 \mu \mathrm{m}$ (A), $32.5 \mu \mathrm{m}$ (B,C). 
has been shown to cause translocation of AQP2 to the plasma membrane in kidney epithelial cells (Bouley et al., 2000, 2005). Furthermore, cGMP production is tightly linked to the nitric oxide system, the soluble form of guanylate cyclase being activated by nitric oxide (Semaan et al., 2005). Excess nitric oxide production is believed to mediate ototoxicity induced by cisplatin and aminoglycosides by stimulating the production of reactive oxygen species (Semaan et al., 2005; Hong et al., 2006; Rybak et al., 2009). In addition, nitric oxide has been implicated in mediating ototoxic effects associated with endolymphatic hydrops; surgical induction of endolymphatic hydrops results in the upregulation of nitric oxide synthase II in cochlear and vestibular cells (Semaan et al., 2005). Exactly what the role is for nitric oxidemediated induction of cGMP, or cGMP produced by soluble guanylate cyclases in response to other signals in the inner ear is not known. Thus, the role for PDE9A and PDE10A in cGMP-related processes needs further investigation. With regard to another cGMP-degrading PDE, PDE5 (a cGMP-specific enzyme), vertigo, and sudden hearing loss have been observed in patients treated with PDE5 inhibitors for erectile dysfunction (Maddox et al., 2009). We were not able to detect PDE5 in human saccule (unpublished observation).

In this work, in addition to AQP2 as was discussed above, several other potential downstream targets of the cAMP-cGMP-PDE signaling networks were detected in the sensory epithelium of the saccule, such as AQP4 and AQP9 (Yamamoto et al., 2002; Zelenina, 2010). For example, vasopressin has been shown to activate water permeability of AQP4 in renal epithelial cells via vasopressin type 2 receptors linked to cAMP production (Zelenina, 2010), and cAMP has been shown to increase AQP4 production in astrocytes (Nicchia et al., 2008). Co-localization of AQP4 and laminin $\gamma 1$ noted in this study is in agreement with co-localization of AQP4 and $\alpha$-dystroglycan, a laminin receptor, in vestibular supporting cells in humans (Lopez et al., 2007; Ishiyama et al., 2009). AQP4 appears to have an important role in the regulation of water homeostasis in the brain, by transporting water at blood-brain and ependymal-cerebrospinal barriers (Zador et al., 2009). A similar role has been suggested in the inner ear when it comes to water transport in-between blood, endolymph, and perilymph compartments. Furthermore, decreased expression of AQP4 in the macula utriculi of patients with Meniere's disease has been reported (Ishiyama et al., 2010). The expression of AQP9 in astrocytes has been shown to be up-regulated by activation of cAMP-dependent protein kinase (Yamamoto et al., 2002). We found that AQP9 was partly localized to the basolateral part of the sensory epithelium as shown by co-staining with laminin 1 . On the other hand, Huang et al. (2002) detected AQP9 mainly at the surface of the sensory epithelium of mouse saccule, indicating a species difference. The importance for AQP4 and AQP9 as targets for cyclic nucleotide signaling in the vestibular systems remains to be established.

The detection of two other cAMP-regulated signaling component, SIK1, and the $\alpha-1$ subunit of $\mathrm{Na}^{+}, \mathrm{K}^{+}$-ATPase, in human saccule sensory epithelium is interesting (Okamoto et al., 2004;
Taub et al., 2004, 2010; Matlhagela et al., 2005; Jaitovich and Bertorello, 2010). In the kidney, SIK1 is believed to be an important regulator of $\mathrm{Na}^{+}, \mathrm{K}^{+}$-ATPase, a critical target for natriuretic and anti-natriuretic factors in the renal proximal tubule. The expression pattern of $\alpha$ - and $\beta$-subunits of the $\mathrm{Na}^{+}, \mathrm{K}^{+}$-ATPase has previously been studied in the developing vestibular system in mice (Peters et al., 2001). With regard to the $\alpha-1$ subunit of $\mathrm{Na}^{+}$, $\mathrm{K}^{+}$-ATPase, Peters et al. (2001) primarily found immunostaining in transitional cells and dark cells which is in contrast to our results showing high expression also in the sensory epithelium in human saccule which could indicate species differences. Interestingly, AQP4 has been shown to interact with $\mathrm{Na}^{+}, \mathrm{K}^{+}$ATPase in astrocytes (Illarionova et al., 2010). Whether there is a SIK1-Na ${ }^{+}, \mathrm{K}^{+}$-ATPase-AQP4 connection in the inner ear and in the human saccule is not known and needs to be further evaluated.

In summary (Figure 6), several PDEs and potential downstream targets of cAMP and cGMP signaling networks such as AQPs 2, 4, 9, SIK1, and the $\alpha-1$ subunit of $\mathrm{Na}^{+}, \mathrm{K}^{+}$-ATPase were detected in human saccule sensory epithelium. To our knowledge PDEs and SIK1 are new actors in the vestibular system and the importance of these proteins in signaling networks regulating AQPs, $\mathrm{Na}^{+}, \mathrm{K}^{+}$-ATPases, and other components of relevance for water and ion homeostasis remains to be established. It is also important to verify the findings using other techniques than immunohistochemistry since there is a potential for non specific staining. Regarding the potential role in water and ion homeostasis for the components studied, this can be discussed in the context of radial flow of endolymph. A number of studies challenge the largely accepted longitudinal flow theory which suggests that endolymph is produced in the cochlear duct and flows in an unidirectional pattern toward the endolymphatic sac, where resorption occurs (Guild, 1927). The radial flow theory postulates that endolymph is produced and absorbed throughout the endolymphatic space. For example, using ionic markers Salt and Ma (2001) provided evidence that control of endolymph homeostasis is distributed throughout the endolymphatic space. In addition, a study using microscale analysis of proteins in the inner ear tissues and fluids with emphasis on the endolymphatic sac, otoconia, and organ of corti support the existence of marked regional differences in the mode and rate of endolymph protein regulation implicating the role of various locally acting molecules and ion channels in endolymph homeostasis (Thalmann et al, 2006).

\section{ACKNOWLEDGMENTS}

The authors would like to acknowledge Gunnel Roos and AnnKristin Holmén-Pålbrink for excellent technical assistance. The authors would also like to acknowledge the staff at the surgical ward at the Department of Neurosurgery. This work was supported by the Swedish Research Council Project 3362 (to Eva Degerman) and 2611 (to Måns Magnusson); the Swedish Diabetes Association; the Swedish Society of Medicine; the A. Påhlsson foundation and the Novo Nordisk Foundation, Denmark. 


\section{REFERENCES}

Agrawal, S., Anderson, P., Durbeej, M., van Rooijen, N., Ivars, F., Opdenakker, G., and Sorokin, L. M. (2006). Dystroglycan is selectively cleaved at the parenchymal basement membrane at sites of leukocyte extravasation in experimental autoimmune encephalomyelitis. J. Exp. Med. 203, 1007-1019.

Ahluwalia, A., MacAllister, R. J., and Hobbs, A. J. (2004). Vascular actions of natriuretic peptides. Cyclic GMPdependent and -independent mechanisms. Basic Res. Cardiol. 99, 83-89.

Andrews, J. C. (2004). Intralabyrinthine fluid dynamics: Meniere disease. Curr. Opin. Otolaryngol. Head Neck Surg. 12, 408-412.

Borghi, C., Modugno, G. C., Brandolini, C., and Pirodda, A. (2006). Is there a role for atrial peptides in the labyrinthine "disease"? Med. Hypotheses 66, 1188-1190.

Bouley, R., Breton, S., Sun, T., McLaughlin, M., Nsumu, NN., Lin, HY., Ausiello, DA., and Brown, D. (2000). Nitric oxide and atrial natriuretic factor stimulate cGMP-dependent membrane insertion of aquaporin 2 in renal epithelial cells. J. Clin. Invest. 106, 1115-1126.

Bouley, R., Pastor-Soler, N., Cohen, O., McLaughlin, M., Breton, S., and Brown, D. (2005). Stimulation of AQP2 membrane insertion in renal epithelial cells in vitro and in vivo by the cGMP phosphodiesterase inhibitor sildenafil citrate (Viagra). Am. J. Physiol. Renal Physiol. 288, 1103-1112.

Conti, M., and Beavo, J. (2007). Biochemistry and physiology of cyclic nucleotide phosphodiesterases: essential components in cyclic nucleotide signaling. Annu. Rev. Biochem. 76, 481-511.

Fessenden, J. D., and Schacht, J. (1998). The nitric oxide/cyclic GMP pathway: a potential major regulator of cochlear physiology. Hear. Res. 118, 168-176.

Guild, S. R. (1927). The circulation of the endolymph. Am. J. Anat. 39, 57-81.

Heimann, E., Jones, H. A., Resjö, S., Manganiello, V. C., Stenson, L., and Degerman, E. (2010). Expression and regulation of cyclic nucleotide phosphodiesterases in human and rat pancreatic islets. PLoS ONE 5, e14191. doi: 10.1371/journal.pone.0014191

Hong, S. H., Park, S. K., Cho, Y. S., Lee, H. S., Kim, K. R., Kim, M. G., and Chung, W. H. (2006). Gentamicin induced nitric oxide-related oxidative damages on vestibular afferents in the guinea pig. Hear. Res. 211, 46-53.
Houslay, M. D. (2010). Underpinning compartmentalised cAMP signalling through targeted cAMP breakdown. Trends Biochem. Sci. 35, 91-100.

Huang, D., Chen, P., Chen, S., Nagura, M., Lim, D. J., and Lin, X. (2002). Expression patterns of aquaporins in the inner ear: evidence for concerted actions of multiple types of aquaporins to facilitate water transport in the cochlea. Hear. Res. 165, 85-95.

Illarionova, N. B., Gunnarson, E., Li, Y., Brismar, H., Bondar, A., Zelenin, S., and Aperia, A. (2010). Functional and molecular interactions between aquaporins and $\mathrm{Na}, \mathrm{K}$-ATPase. $\mathrm{Neu}$ roscience $168,915-925$.

Ishiyama, A., Mowry, S. E., Lopez, I. A., and Ishiyama, G. (2009). Immunohistochemical distribution of basement membrane proteins in the human inner ear from older subjects. Hear. Res. 254, 1-14.

Ishiyama, G., Lopez, I. A., BeltranParrazal, L., and Ishiyama, A. (2010). Immunohistochemical localization and mRNA expression of aquaporins in the macula utriculi of patients with Meniere's disease and acoustic neuroma. Cell Tissue Res. 340, 407-419.

Jaitovich, A., and Bertorello, A. M. (2010). Intracellular sodium sensing: SIK1 network, hormone action and high blood pressure. Biochim. Biophys. Acta 1802, 1140-1149.

Kakigi, A., Nishimura, M., Takeda, T., Taguchi, D., and Nishioka, R. (2009). Expression of aquaporin1, 3, and 4, NKCC1, and NKCC2 in the human endolymphatic sac. Auris Nasus Larynx 36, 135-139.

Kobayashi, N., Kobayashi, N., Yamaguchi, A., and Nishi, T. (2009). Characterization of the ATPdependent sphingosine 1-phosphate transporter in rat erythrocytes. J. Biol. Chem. 284, 21192-21200.

Kuijpers, W., and Bonting, S. L. (1970). The cochlear potentials. II. The nature of the cochlear endolymphatic resting potential. Pflugers Arch. 320, 359-372.

Lang, F., Vallon, V., Knipper, M., and Wangemann, P. (2007). Functional significance of channels and transporters expressed in the inner ear and kidney. Am. J. Physiol. Cell Physiol. 293, 1187-1208.

Long, L., Tang, Y., Xia, Q., Xia, Z., and Liu, J. (2010). The expression of atrial natriuretic peptide receptor in the mouse inner ear labyrinth. Neuro Endocrinol. Lett. 31, 126-130.

Lopez, I. A., Ishiyama, G., Lee, M., Baloh, R. W., and Ishiyama, A. (2007). Immunohistochemical localization of aquaporins in the human inner ear. Cell Tissue Res. 328, 453-460.
Maddox, P. T., Saunders, J., and Chandrasekhar, S. S. (2009). Sudden hearing loss from PDE-5 inhibitors: a possible cellular stress etiology. Laryngoscope 119, 1586-1589.

Maekawa, C., Kitahara, T., Kizawa, K., Okazaki, S., Kamakura, T., Horii, A., Imai, T., Doi, K., Inohara, H. and Kiyama, H. (2010). Expression and translocation of aquaporin-2 in the endolymphatic sac in patients with Meniere's disease. J. Neuroendocrinol. 22, 1157-1164.

Manganiello, V. C., Ahmad, F., Fontana J., and Degerman, E. (2006). "Cyclic nucleotide phosphodiesterase," in Encyclopedia of Respiratory Medicine, Vol. 1. eds G. Laurent and S. Shapiro (Oxford: Elsevier), 589-594.

Matlhagela, K., Borsick, M., Rajkhowa T., and Taub, M. (2005). Identification of prostaglandin-responsive element in the $\mathrm{Na}$, K-ATPase beta 1 promoter that is regulated by cAMP and $\mathrm{Ca} 2+$. Evidence for an interactive role of cAMP regulatory element-binding protein and Sp1. J. Biol. Chem. 280, 334-346.

Milhaud, P. G., Pondugula, S. R., Lee, J. H., Herzog, M., Lehouelleur, J., Wangemann, P., Sans, A., and Marcus, D. C. (2002). Chloride secretion by semicircular canal duct epithelium is stimulated via beta 2 adrenergic receptors. Am. J. Physiol. Cell Physiol. 283, 1752-1760.

Nicchia, G. P., Cogotzi, L., Rossi, A., Basco, D., Brancaccio, A., Svelto, M., and Frigeri, A. (2008). Expression of multiple AQP4 pools in the plasma membrane and their association with the dystrophin complex. J. Neurochem. 105, 2156-2165.

Nilsson, R., Ahmad, F., Swärd, K. Andersson, U., Weston, M., Manganiello, V., and Degerman, E. (2006). Plasma membrane cyclic nucleotide phosphodiesterase $3 \mathrm{~B}$ (PDE3B) is associated with caveolae in primary adipocytes. Cell Signal. $18,1713-1721$.

Noda, Y., Sohara, E., Ohta, E., and Sasaki S. (2010). Aquaporins in kidney pathophysiology. Nat. Rev. Nephrol. 6, 168-178.

Noël, G., Tham, D. K., and Moukhles, H. (2009). Interdependence of lamininmediated clustering of lipid rafts and the dystrophin complex in astrocytes. J. Biol. Chem. 284, 19694-19704.

Okamoto, M., Takemori, H., and Katoh, Y. (2004). Salt-inducible kinase in steroidogenesis and adipogenesis. Trends Endocrinol. Metab. 15, 21-26.

Peters, T. A., Kuijpers, W., and Curfs, J. H. (2001). Occurrence of NaK-ATPase isoforms during rat inner ear development and functional implications.
Eur. Arch. Otorhinolaryngol. 258, 67-73.

Pirodda, A., Ferri, G. G., Modugno, G. C., and Borghi, C. (2001). Systemic hypotension and the development of acute sensorineural hearing loss in young healthy subjects. Arch. Otolaryngol. Head Neck Surg. 127, 1049-1052.

Pirodda, A., Saggese, D., Ferri, G. G., Giausa, G., Grippo, M. C., and Gaddi, A. (1997). The role of hypotension in the pathogenesis of sudden hearing loss. Audiology 36, 98-108.

Rybak, L. P., Mukherjea, D., Jajoo, S., and Ramkumar, V. (2009). Cisplatin ototoxicity and protection: clinical and experimental studies. Tohoku J. Exp. Med. 219, 177-186.

Salt, A. N., and Ma, Y. (2001). Quantification of solute entry into cochlear perilymph through the round window membrane. Hear Res. 154, 88-97.

Salt, A. N., and Plontke, S. K. (2010). Endolymphatic hydrops: pathophysiology and experimental models. Otolaryngol. Clin. North Am. 43, 971-983.

Sanes, J. R., Engvall, E., Butkowski, R., and Hunter, D. D. (1990). Molecular heterogeneity of basal laminae: isoforms of laminin and collagen IV at the neuromuscular junction and elsewhere. J. Cell Biol. 111, 1685-1699.

Semaan, M. T., Alagramam, K. N., and Megerian, C. A. (2005). The basic science of Meniere's disease and endolymphatic hydrops. Curr Opin. Otolaryngol. Head Neck Surg. 13, 301-307.

Sjöström, M., Stenström, K., Eneling, K., Zwiller, J., Katz, AI., Takemori, H., and Bertorello, A. M. (2007). SIK1 is part of a cell sodium-sensing network that regulates active sodium transport through a calciumdependent process. Proc. Natl. Acad. Sci. U.S.A. 104, 16922-16927.

Stefan, E., Wiesner, B., Baillie, GS., Mollajew, R., Henn, V., Lorenz, D., Furkert, J., Santamaria, K., Nedvetsky, P., Hundsrucker, C., Beyermann, M., Krause, E., Pohl, P., Gall, I., MacIntyre, A. N., Bachmann, S., Houslay, M. D., Rosenthal, W., and Klussmann, E. (2007). Compartmentalization of cAMP-dependent signaling by phosphodiesterase-4D is involved in the regulation of vasopressin-mediated water reabsorption in renal principal cells. $J$. Am. Soc. Nephrol. 18, 199-212.

Takeda, T., and Taguchi, D. (2009). Aquaporins as potential drug targets for Meniere's disease and its related diseases. Handb. Exp. Pharmacol. 190, 171-184. 
Takeda, T., Takeda, S., Kakigi, A., Okada, T., Nishioka, R., Taguchi, D., and Nishimura, M, Nakatani, H D. (2010). Hormonal aspects of Ménière's disease on the basis of clinical and experimental studies. ORL J. Otorhinolaryngol. Relat. Spec. 71(Suppl. 1), 1-9.

Taub, M., Borsick, M., Geisel, J., Matlhagela, K., Rajkhowa, T., and Allen, C. (2004). Regulation of the $\mathrm{Na}$, K-ATPase in MDCK cells by prostaglandin E1: a role for calcium as well as cAMP. Exp. Cell Res. 299, 1-14.

Taub, M., Springate, J. E., and Cutuli, F. (2010). Targeting of renal proximal tubule $\mathrm{Na}$, K-ATPase by salt-inducible kinase. Biochem. Biophys. Res. Commun. 393, 339-344.

Thalmann, I., Hughes, I., Tong, B. D., Ornitz, D. M., and Thalmann, R. (2006). Microscale analysis of proteins in inner ear tissues and fluids with emphasis on endolymphatic sac, otoconia, and organ of Corti. Electrophoresis 27, 1598-1608.

Wangemann, P. (2002). K(+) cycling and its regulation in the cochlea and the vestibular labyrinth. Audiol. Neurootol. 7, 199-205.

Wangemann, P., Liu, J., Shimozono, M., and Scofield, M. A. (1999). Betal-adrenergic receptors but not beta2-adrenergic or vasopressin receptors regulate $\mathrm{K}+$ secretion in vestibular dark cells of the inner ear. J. Membr. Biol. 170, 67-77.

Yamamoto, N., Sobue, K., Fujita, M., Katsuya, H., and Asai, K. (2002). Differential regulation of aquaporin-5 and -9 expression in astrocytes by protein kinase A. Brain Res. Mol. Brain Res. 104, 96-102.

Yang, Y., Dai, M., Wilson, T. M., Omelchenko, I., Klimek, J. E., Wilmarth, P. A., David, L. L., Nuttall, A. L., Gillespie, P. G., and Shi, X. (2011). Na+/K+-ATPase al identified as an abundant protein in the blood-labyrinth barrier that plays an essential role in the barrier integrity. PLOS ONE 6, e16547. doi: 10.1371/journal.pone. 0016547

Yoon, Y. S., Seo, W. Y., Lee, M. W., Kim, S. T., and Koo, S. H. (2009). Saltinducible kinase regulates hepatic lipogenesis by controlling SREBP-1c phosphorylation. J. Biol. Chem. 284, 10446-10452.

Zador, Z., Stiver, S., Wang, V., and Manley, G. T. (2009). Role of aquaporin-4 in cerebral edema and stroke. Handb. Exp. Pharmacol. 190, 159-170.

Zelenina, M. (2010). Regulation of brain aquaporins. Neurochem. Int. $57,468-488$.

Conflict of Interest Statement: The authors declare that the research was conducted in the absence of any commercial or financial relationships that could be construed as a potential conflict of interest.

Received: 06 May 2011; paper pending published: 22 June 2011; accepted: 13 July 2011; published online: 05 August 2011. Citation: Degerman E, Rauch $U$, Göransson $O$, Lindberg S, Hultgårdh $A$ and Magnusson M (2011) Identification of new signaling components in the sensory epithelium of human saccule. Front. Neur. 2:48. doi: 10.3389/fneur.2011.00048

This article was submitted to Frontiers in Neuro-otology, a specialty of Frontiers in Neurology.

Copyright (c) 2011 Degerman, Rauch, Göransson, Lindberg, Hultgårdh and Magnusson. This is an open-access article subject to a non-exclusive license between the authors and Frontiers Media $S A$, which permits use, distribution and reproduction in other forums, provided the original authors and source are credited and other Frontiers conditions are complied with. 